\title{
MENUMBUHKAN TECHNOPRENEURSHIP PADA IBU-IBU PKK GUNA MENINGKATKAN PEREKONOMIAN DI ERA PANDEMI COVID-19
}

\author{
Hasundungan Pangaribuan ${ }^{1}$, Randhy Agusentoso ${ }^{2}$, Windy Gustia Wardani ${ }^{3}$ \\ Universitas Pamulang \\ Email : $\underline{1}$ dosen01644@unpam.ac.id ${ }^{2}$ dosen01619@unpam.ac.id ${ }^{3}$ dosen01579@unpam.ac.id
}

\begin{abstract}
Community service activities are one of the components in the Tridharma of Higher Education. Because every lecturer has an obligation to do community service. The dedication carried out in this proposal is to increase the income of community groups of PKK mothers through several handicrafts. In addition, this service activity also aims to support government programs to overcome national economic problems due to the impact of the Covid 19 outbreak. The targets for community service are PKK women around Bulak Cinangka village, Sawangan District, Depok City. This service program is carried out for a period of 3 days. The method used in this service is training and also assistance on creating small and medium business opportunities. The results of this dedication show that the boarding school residents are very enthusiastic about participating in this training. Furthermore, with the implementation of this service activity, the community, especially PKK mothers, has the ability to create opportunities for small and medium enterprises in the conditions of the Covid 19 outbreak.For further community service activities, it is hoped that they will be able to provide continuous training that triggers the spirit of the boarding school residents to generate their own income to improve the welfare of the residents of the Sawangan Depok environment.
\end{abstract}

Keywords: Creating Business Opportunities; Business Unit; Capacity; PKK Mother

\begin{abstract}
ABSTRAK
Kegiatan pengabdian masyarakat merupakan salah satu komponen dalam Tridharma Perguruan Tinggi. Oleh karena setiap dosen memiliki kewajiban untuk melakukan pengabdian kepada masyarakat. Pengabdian yang dilakukan dalam proposal ini adalah guna meningkatkan pendapatan kelompok-kelompok masyarakat ibu-ibu PKK melalui beberapa handycrafts. Selain itu, kegiatan pengabdian ini juga memiliki tujuan untuk mendukung program pemerintah untuk mengatasi permasalahan ekonomi nasional dikarenakan dampak wabah Covid 19. Adapun sasaran pada pengabdian masyarakat ini adalah ibu-ibu PKK sekitar kampung bulak Cinangka Kecamatan Sawangan Kota Depok. Program pengabdian ini dilaksanakan selama kurun waktu 3 hari. Metode yang digunakan dalam pengabdian ini adalah pelatihan dan juga pendampingan tentang menciptakan peluang usaha kecil dan menengah. Hasil pengabdian ini menunjukkan bahwa warga ponpes sangat antusias mengikuti pelatihan ini. Lebih lanjut, dengan dilaksanakannya kegiatan pengabdian ini, masyarakat
\end{abstract}


khususnya ibu-ibu PKK memiliki kemampuan untuk menciptakan peluang usaha kecil dan menengah dalam kondisi wabah Covid 19. Untuk kegiatan pengabdian selanjutnya diharapkan mampu memberikan pelatihan yang berkelanjutan yang memicu semangat warga ponpes untuk menghasilkan pendapatan sendiri demi meningkatkan kesejahteraan kehidupan warga Sawangan Depok.

Kata kunci : Menciptakan peluang usaha; Unit Usaha; Kapasitas; Ibu PKK

\section{A. PENDAHULUAN}

Saat ini Perekonomian di Negara Indonesia sangat menurun, di mana terjadi pandemi di seluruh dunia menyebabkan ekonomi Indonesia mengalami resesi Begitu juga dengan perekonomi global yang juga mengalami resesi. Pertumbuhan ekonomi Indonesia minus hingga 5,32 persen pada triwulan II 2020, Angkanya sempat membaik, meski masih dalam kategori minus yaitu 3,49 persen Dampak dari minusnya pertumbuhan ekonomi ini, menurut Nailul, salah satunya adalah peningkatan angka pengangguran dan penduduk miskin. Dalam Kegiatan ini mengalami beberapa hambatan. Ada sejumlah permasalahan umum yang dihadapi antara lain keterbatasan modal kerja maupun investasi, kesulitan dalam pemasaran, distribusi dan pengadaan bahan baku dan input lainnya, keterbatasan masyarakat dengan kreatifitas dan keahlian yang tinggi (kualitas SDM rendah) dan kemampuan teknologi, sehingga produk yang dihasilkan tidak mampu bersaing di pasaran. Sehubungan dengan hal tersebut, perlu dilakukan kajian dan dipecahkan melalui pemberdayaan kepada Masyarakat dengan Optimalisasi berbasis Technopreneurship pada ibu-ibu PKK. Guna meningkatkan pendapatan kelompok-kelompok masyarakat ibu-ibu PKK melalui beberapa handycrafts.

\section{B. METODE PELAKSANAAN \\ Teknik dan Tahapan}

Teknik dan tahapan sosialisasi Technopreneurship dalam Pengabdian Kepada Masyarakat :

1. Survey Lokasi tempat Pengabdian Kepada Masyarakat yang ingin dijadikan tempat Praktek

2. Melaksanakan sosialisasi dengan memperkenalkan Manfaat-manfaat teknologi dan Bisnis

3. Mengajak Masyarakat Mengeksplorisasi dan Mengapresiasi karya-karya di sekeliling Perkampungan sebagai wujud nyata kepedulian serta menjadi bentuk apresiasi

4. Membangun Kreativitas Masyarakat.

\section{Tujuan Program}

Tujuan Program yang hendak dicapai dalam tahapan pekerjaan diatas adalah :

1. Masyarakat diharapkan dapat memaksimalkan pemanfaatan teknologi dengan Bisnis

2. Menghasilkan Produk Baru

3. Menambah Perekonomian di Keluarga

4. Percaya Diri dan Terampil

\section{Solusi Permasalahan}

Dengan strategi pemasaran yang baik, maka besaran potensi untuk mendapatkan kesuksesan di pasaran akan didapatkan. Pastikan Anda merencanakan dengan tepat mulai dari biaya, promosi produk, tempat, target promosi hingga media untuk berpromosi. Rencanakan seluruh anggaran secara rinci sehingga Anda bisa menghitung segala kemungkinan yang ada.

Program technopreneurship di kampus rupanya memberi dampak positif terhadap kemampuan lulusan untuk bergerak dalam sektor e-commerce. Direktur Kehumasan dan 
Urusan Internasional Universitas AMIKOM Yogyakarta Erik Hadi Saputra mengatakan, di kampusnya bahkan pengenalan terhadap digital technology telah diperkenalkan sejak dini.

"Di awal kita ubah mindsetnya menjadi seorang technopreneur," kata dia, Kamis (3/8). Kemudian dilanjutkan dengan program karakter positif. Intinya, kata dia, pada semester awal dilakukan pembinaan terhadap karakter personal mahasiswa. Lalu pada tahapan selanjutnya, pihak kampus telah menyiapkan satu konsep lingkungan digital teknologi untuk membiasakan para mahasiswa dan menumbuhkan semangat menjadi seorang technopreneur. "Semua harus mereka dapatkan. Setelah itu baru mereka fokus pada bidang e-commerce," katanya.

Fokus pada e-commerce ini didasarkan pada minat masing-masing para mahasiswa. Dalam tahap ini, mahasiswa diajak untuk memahami fokus tema yang dipilih, baik dari sisi hukum, bahasa yang digunakan, ekonomi dan budaya. Diakui Erik, adanya program technopreneurship berdampak besar. Program yang sudah ada sejak 23 tahun lalu ini rupanya telah menelurkan mahasiswa berprestasi. Pada, semester tiga, banyak yang telah memiliki bisnis e-commerce yang pendapatannya melebihi pendpaatan dosesn-dosennya.

"Bisa sebulan dapat Rp 100 juta. Tetapi memang di bisnis e-commerce harus punya ketekunan dan bagaimana memaksimalkan potensi," ujarnya. Sementara itu Anggota Himpunan Pengusaha Muda Indonesia (HIPMI) Anthony Leong mengatakan, pihaknya kerap melakukan pelatihan-pelatihan terkait e-commerce termasuk digital teknolgi di dalamnya, meski belum terstruktur. Solusinya : sebelum menjadi entrepreneur Anda perlu meningkatkan kualitas dan kemampuan menjual Anda. Mulai dari cara mempengaruhi orang lain, melakukan pendekatan persuasif, mengenali kebutuhan konsumen, mempresentasikan solusi (layanan atau produk), melakukan closing, follow up dan lain sebagainya. Mau pemasaran dengan offline atau online pada dasarnya sama, cuma beda cara pendekatannya.

\section{Aspek Permasalahan Pemasaran}

Menurut Stanton dalam Tambajong (2013:1293), Pemasaran adalah suatu sistem dari kegiatan bisnis yang dirancang untuk merencanakan, menentukan harga, mempromosikan dan mendistribusikan produk yang dapat memuaskan keinginan dalam mencapai tujuan perusahaan.

Adapun Aspek-aspek Permasalahan Pemasaran :

1. Kurangnya kapabilitas dalam mengelola bisnisnya secara profesional

2. Pengetahuan Tentang Pemasaran e-commerce

3. Perluasan jangkauan pasar secara offline pada toko dan minimarket sekitar

4. Pemanfaatan teknologi informasi pemasaran online melalui e-marketplace dan aplikasi social media

\section{Aspek Permasalahan SDM}

Menurut Mathis dan Jackson, sumber daya manusia (SDM) merupakan suatu rancangan sistem-sistem formal dalam suatu organisasi untuk memastikan penggunaan bakat dan potensi manusia secara efektif dan efisien agar bisa mencapai tujuan organisasi.

Adapun Aspek Permasalahan SDM :

1. Menganggap Remeh Pelatihan SDM

2. Kebijakan yang Kurang memadai

3. Penggolongan SDM Secara Asal

\section{Aspek Permasahan Keuangan}

Menurut Liefman, Manajemen Keuangan merupakan usaha untuk menyediakan uang dan menggunakan uang untuk mendapat atau memperoleh aktiva. 
Adapun Aspek Permasalahan Keuangan :

1. Tidak ada pemisahan antara uang usaha dan uang pribadi

2. Tidak memiliki perencanaan uang yang matang

3. Tidak memiliki Laporan Keuangan

\section{Desain Pemecahan Masalah}

Hal yang mendasarkan pada kegiatan ini adalah sebuah kegiatan pengabdian melalui melakukan sosialisasi langsung di Masyarakat, khususnya di Ibu-ibu PKK di Cinangka, Sawangan-Depok. Dikemas dengan Nama Kegiatan "Menumbuhkan Technopreneurship Pada Ibu-Ibu Pkk Guna Meningkatkan Perekonomian Di Era Pandemi Covid-19” untuk lebih jelasnya dapat dilihat dari skema di bawah ini:

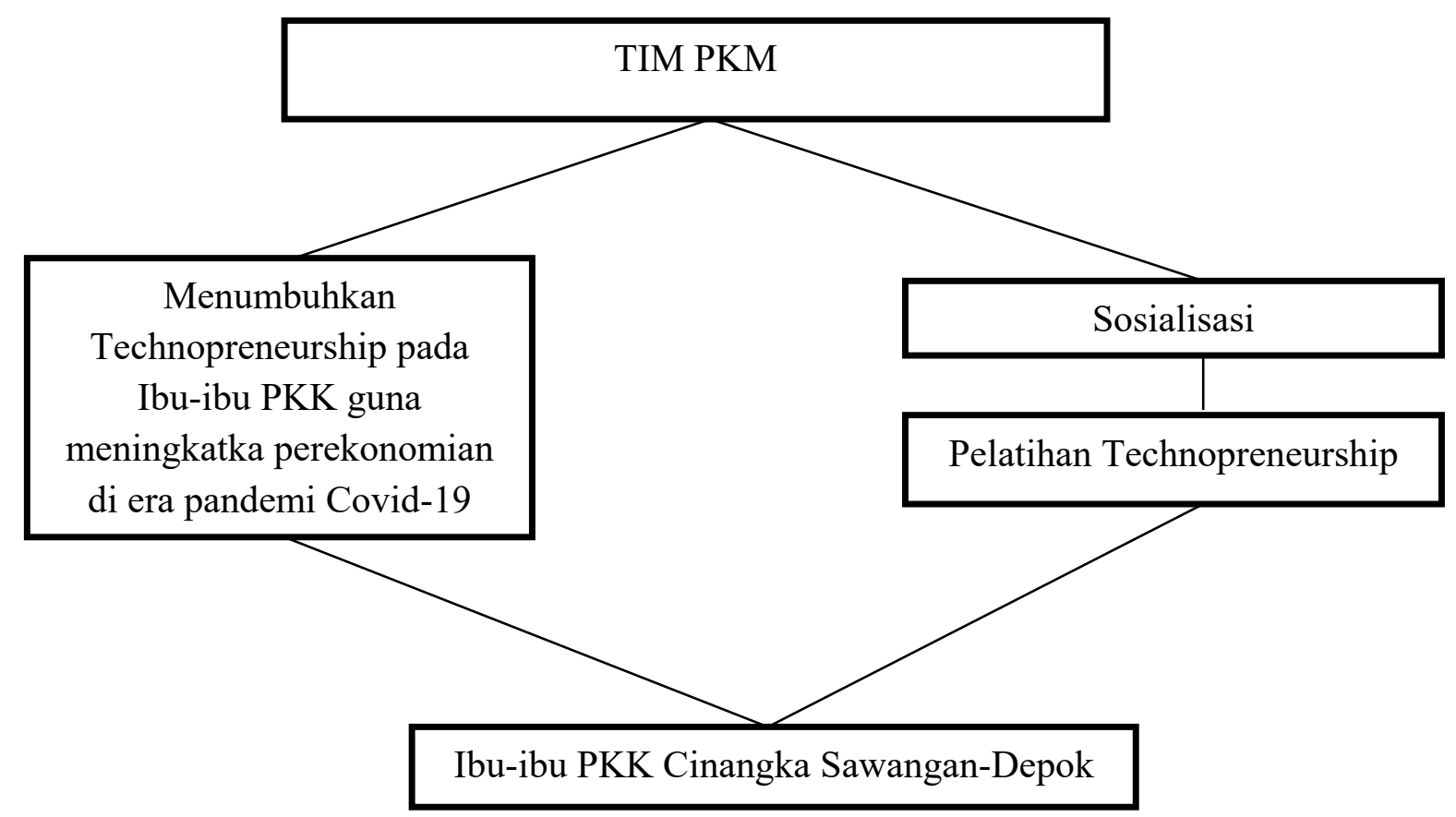

\section{Gambar 1 Desain Pemecahan Masalah}

\section{HASIL DAN PEMBAHASAN}

Profil Pemberdayaan dan Kesejahteraan Keluarga (PKK) RW.05 Cinangka SawanganDepok

Pemberdayaan Kesejahteraan Keluarga (PKK) sebagai gerakan pembangunan masyarakat bermula dari seminar Home Economic di Bogor tahun 1957. Sebagai tindak lanjut dari seminar tersebut, pada tahun 1961 panitia penyusunan tata susunan pelajaran pada Pendidikan Kesejahteraan Keluarga (PKK), Kementerian Pendidikan bersama kementeriankementerian lainnya menyusun 10 segi kehidupan keluarga. Gerakan PKK dimasyarakatkan berawal dari kepedulian istri gubernur Jawa Tengah pada tahun 1967 (Ibu Isriati Moenadi) setelah melihat keadaan masyarakat yang menderita busung lapar.

Upaya untuk meningkatkan kesejahteraan keluarga melalui 10 segi pokok keluarga dengan membentuk Tim Penggerak PKK di semua tingkatan, yang keanggotaan timnya secara relawan dan terdiri dari tokoh/pemuka masyarakat, para isteri kepala dinas/jawatan 
dan isteri kepala daerah s.d tingkat desa dan kelurahan yang kegiatannya didukung dengan anggaran pendapatan dan belanja daerah.

Pada tanggal 27 Desember 1972 mendagri mengeluarkan surat kawat no. Sus 3/6/12 kepada seluruh gubernur kdh tk. I Jawa Tengah dengan tembusan gubernur kdh seluruh Indonesia, agar mengubah nama pendidikan kesejahteraan keluarga menjadi pembinaan kesejahteraan keluarga. Sejak itu gerakan PKK dilaksanakan di seluruh Indonesia dengan nama Pembinaan Kesejahteraan Keluarga (PKK), dan tanggal 27 Desember ditetapkan sebagai "hari kesatuan gerak PKK" yang diperingati pada setiap tahun.

Pada era reformasi dan ditetapkannya TAP MPR no. IV/MPR/1999 tentang GBHN 1999-2004, serta pelaksanaan otonomi daerah berdasarkan undang-undang no.22 tahun 1999 dan undang-undang no.25 tahun 1999, tetapi PKK pusat tanggap dengan mengadakan penyesuaian-penyesuaian yang disepakati dalam rakernaslub PKK tanggal 31 Oktober s.d 2 November 2000 di Bandung dan hasilnya merupakan dasar dalam perumusan keputusan menteri dalam negeri dan otonomi daerah no. 53 tahun 2000, yang selanjutnya dijabarkan dalam pedoman umum gerakan Pemberdayaan dan Kesejahteraan Keluarga (PKK) ini.

Pemberdayaan Kesejahteraan Keluarga, disingkat PKK, adalah organisasi kemasyarakatan yang memberdayakan wanita untuk turut berpartisipasi dalam pembangunan Indonesia.

Program Pokok PKK Cinangka Sawangan Depok ini diantaranya adalah :

1. Gotong Royong

2. Pangan

3. Sandang

4. Perumahan dan Tatalaksana Rumah Tangga

5. Kesehatan

6. Pengembangan Kehidupan Berkoperasi

7. Kelestarian Lingkungan Hidup

8. Perencanaan Sehat

9. Keagamaan

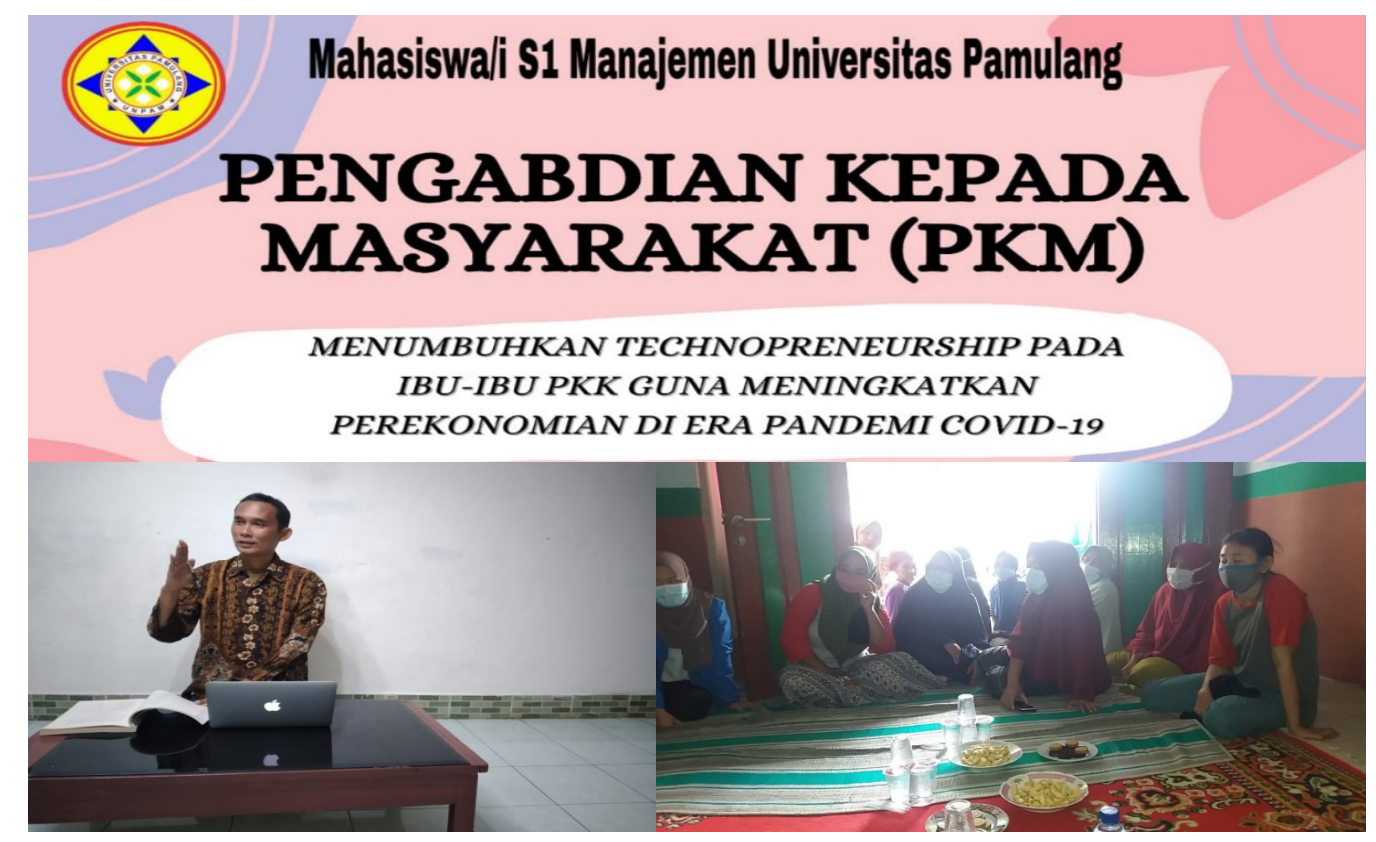

Gambar 2. Penyampaian Materi Oleh Tim PKM 


\section{Hasil dan Pembahasan}

Dari hasil pelaksaan Pengabdian Kepada Masyakat dari Tim Panitia pelaksanaan melakukan evaluasi setelah kegiatan pelatihan kepada Ibu-ibu PKK yaitu dengan cara mengisi instrument yang disediakan oleh TIM Pengabdian Kepada Masyakart terkait bagaimanakah tanggapan para Ibu-ibu PKK Cinangka Sawangan Depok terhadap kegiatan PKM yang dilakukan oleh Mahasiswa/i dan Dosen Pembimbing Manajemen Universitas Pamulang.

\section{Tabel 1 Ketercapaian Target Luaran PKM}

\begin{tabular}{|c|c|c|c|}
\hline No & $\begin{array}{c}\text { Tujuan Kegiatan } \\
\text { PKN }\end{array}$ & $\begin{array}{c}\text { Target Kegiatan } \\
\text { PKM }\end{array}$ & $\begin{array}{c}\text { Hasil Kegiatan } \\
\text { PKM }\end{array}$ \\
\hline 1. & $\begin{array}{l}\text { Memberikan pengetahuan } \\
\text { tentang dan pentingnya } \\
\text { Technopreneurship Pada Ibu- } \\
\text { Ibu PKK Cinangka Sawangan } \\
\text { Depok }\end{array}$ & $\begin{array}{l}\text { Ibu-Ibu } \\
\text { mendapatkan } \\
\text { pengetahuan } \\
\text { tentang } \\
\text { Tehnopreneurship }\end{array}$ & $\begin{array}{l}\text { Tersampaikannya } \\
\text { materi setiap Ibu- } \\
\text { Ibu menerima } \\
\text { materi dengan } \\
\text { baik }\end{array}$ \\
\hline 2. & $\begin{array}{l}\text { Melaksanakan Menggunakan } \\
\text { Smartphone Masing-masing } \\
\text { pada Ibu-Ibu Seperti } \\
\text { Penjualan meggunakan } \\
\text { smartphone di E-commerce }\end{array}$ & $\begin{array}{l}\text { Ibu-Ibu bisa } \\
\text { menjualkan } \\
\text { Produk } \\
\text { Dengan } \\
\text { Smartphone } \\
\text { memanfaatkan } \\
\text { Teknologi yang } \\
\text { maju }\end{array}$ & $\begin{array}{l}\text { Tersampaikannya } \\
\text { materi dimana } \\
\text { Ibu-ibu mengikut } \\
\text { pelatihan, } \\
\text { antusias } \\
\text { semangat. }\end{array}$ \\
\hline 3. & $\begin{array}{l}\text { Memberikan pendampingan } \\
\text { serta bimbingan teknis Kepada } \\
\text { Ibu-Ibu dengan salah satu } \\
\text { produk yang sudah kami pilih } \\
\text { yaitu baju tie dye }\end{array}$ & $\begin{array}{l}\text { Ibu-Ibu PKK } \\
\text { dapat memahami } \\
\text { bagaimana cara } \\
\text { pembuatan baju } \\
\text { Tie dye dan bisa } \\
\text { mempraktikan } \\
\text { dirumah masing- } \\
\text { masing }\end{array}$ & $\begin{array}{l}\text { Tersampaikannya } \\
\text { materi dengan baik } \\
\text { memberikan materi } \\
\text { yang disampaikan } \\
\text { oleh nara sumber } \\
\text { sehingga Ibu-Ibu } \\
\text { PKK dengan } \\
\text { antusias dan } \\
\text { semangat } \\
\text { mengikuti } \\
\text { pelatihan, } \\
\text { disampaikan oleh } \\
\text { nara sumber }\end{array}$ \\
\hline
\end{tabular}

Sumber : Hasil pelaksanaan dan evaluasi TIM PKM 


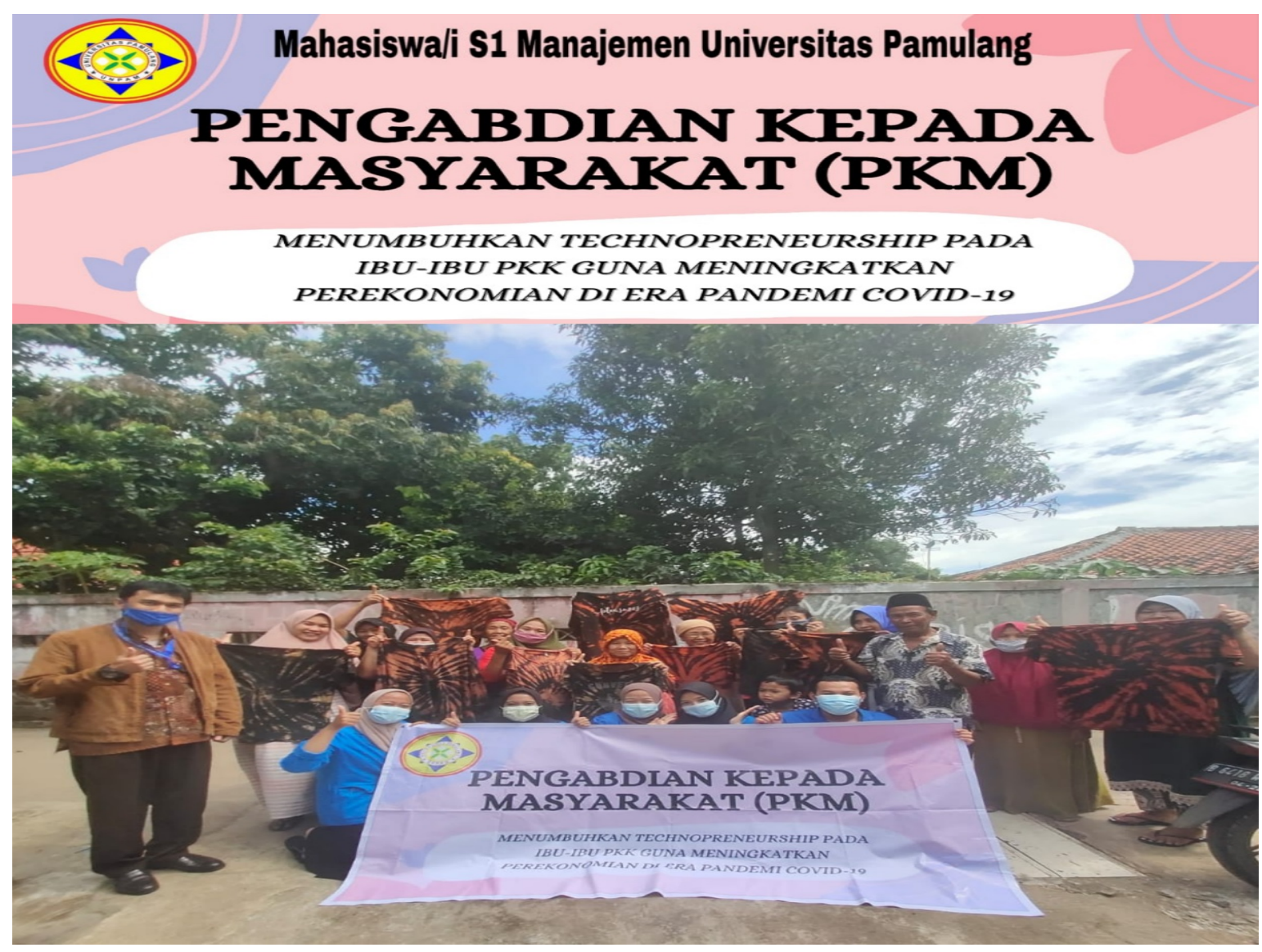

Gambar 3. Foto bersama antara Panitia PKM UNPAM dan Ibu-ibu PKK Cinangka Sawangan Depok

\section{KESIMPULAN DAN SARAN}

\section{Kesimpulan}

Hasil dari kegiatan Pengabdian Kepada Masyakart pada Ibu-Ibu PKK Cinangka Sawangan Depok kami bisa menarik kesimpulan bahwa dengan memanjatkan puji Syukur Alhamdulillah dapat berjalan lancar tanpa ada kendala yang berarti. Materi - materi yang dipersiapkan dapat tersampaikan oleh Mahasiswa/i dari Universitas Pamulang secara baik dan maksimal. Dari pengamatan Tim Pengabdian Kepada Masyakart dari tahapan- tahapan kegiatan yang telah dilakukan dalam kegiatan ini menunjukkan adanya peningkatan pemahaman Ibu-Ibu PKK dalam hal memahami, mempraktekan Technopreneurship dengan baik dan benar. Dilihat juga dari Ibu-Ibu PKK Cinangka Sawangan Depok juga menunjukkan reaksi yang begitu semangat dalam mengikuti kegiatan serta pemahaman peserta pelatihan terhadap daya serap materi yang disajikan juga sangat baik. Kami melakukan evaluasi dengan memberikan beberapa pertanyaan intraktif dan Praktikan Technopreneurship ini knowledge/pengetahuan yang dimiliki peserta pelatihan perihal subyek materi yang disampaikan. Selain itu, pada level psikomotorik atau ketrampilan menunjukkan hasil yang baik yakni mampu melakukan kegiatan praktik yang diberikan oleh Tim Pengabdian Kepada Masyarkat dengan baik. 
Saran

Bagi Ibu-Ibu PKK Cinangka Sawangan Depok, tingkatkan semangat, yang sudah baik ditingkatkan, yang belum baik senantiasa diperbaiki, serta perlu menjaga tensi semangat belajar karena belajar tidak megenal usia hingga pada situasi dan waktu yang tidak ditentukan batas akhirnya.

\section{DAFTAR PUSTAKA}

Ambradi., \& Helmi Chadiri.(2020).Faktor-faktor yang Mempengaruhi Minat Technoprenur Mahasiswa di Era Tekonologi Digital

Edy Ismail., \& Priyanti. (2020).Pengembangan Model Pembelajaran Technoprenurship Berbasis E-learning di Pendemi Covid-19

Jusnita, Denur, Siti Samsiah. (2019). Mewujudkan Kemandiran Pemuda Berbasis Technoprenur Melalui Pelatihan Tune Up Sepeda Motor Di Karang Taruna Labuhan Barat Pekan Baru

Tata, Subari. (2012). Analisis Sistem Informasi Andi.Yogyakarta

https://www.kompas.com/tren/read/2020/12/19/180200765/refleksi-erekonomian-indonesia2020-dan-harapan-pada-2021-?page=all

https://ekonomi.bunghatta.ac.id/index.php/id/artikel/913-pengertian-ekonomi-kreatif-cirijenis-sektor-contoh-dan-perkembangan-ekonomi-kreatif-di-indonesia

https://sis.binus.ac.id/2014/06/19/7120/

https://www.researchgate.net/publication/322343626 technopreneur_berbasis inkubator\#: : :t ext=Terminologi\%20dari\%20para\%20ahli

https://www.jurnal.id/id/blog/perencanaan-dan-komponen-dalam-manajemenbisnis/\#c Memiliki Strategi Pemasaran

https://republika.co.id/berita/ekonomi/makro/17/08/03/ou45ul415-technopreneurshipmunculkan-sdm-berprestasi

https://www.finansialku.com/5-masalah-yang-sering-dihadapi-entrepreneur-bagaimanasolusinya/\#2 Kesulitan Mengelola_Keuangan 